\title{
Intracellular distribution of the ORF4 gene product of varicella- zoster virus is influenced by the IE62 protein
}

\author{
Defechereux $\mathrm{P}^{[1]}$, Debrus $\mathrm{S}^{[1]}$, Baudoux $\mathrm{L}^{[1]}$, Schoonbroodt $\mathrm{S}^{[1]}$, Merville M-P ${ }^{[2]}$, Rentier $\mathrm{B}^{[1]}$ \\ Piette J[1]
}

[1] Laboratory of Fundamental Virology, Department of Microbiology, Institute of Pathology B23, University of Liege, B-4000 Liege, Belgium

${ }^{[2]}$ Laboratory of Clinical Chemistry, Institute of Pathology B23, University of Liege, B-4000 Liege, Belgium

\begin{abstract}
[This is an author manuscript that has been accepted for publication in Journal of General Virology, copyright Society for General Microbiology, but has not been copy-edited, formatted or proofed. Cite this article as appearing in Journal of General Virology. This version of the manuscript may not be duplicated or reproduced, other than for personal use or within the rule of 'Fair Use of Copyrighted Materials' (section 17, Title 17, US Code), without permission from the copyright owner, Society for General Microbiology. The Society for General Microbiology disclaims any responsibility or liability for errors or omissions in this version of the manuscript or in any version derived from it by any other parties. The final copy-edited, published article, which is the version of record, can be found at http://vir.sgmjournals.org, and is freely available without a subscription.]
\end{abstract}

\section{INTRODUCTION}

The course of productive infection by varicella-zoster virus (VZV), the causative agent of chickenpox and shingles, is most probably orchestrated in a sequential and highly ordered manner, as is the case for the prototype system of the subfamily Alphaherpesvirinae, herpes simplex virus type 1 (HSV-1) (Honess \& Roizman, 1974, 1975). Since VZV is highly cell-associated in vitro, studies of its biology have been hindered. Current insight into the regulation of VZV gene expression has been largely gained by analogy with HSV-1 and the more recent appearance of direct molecular analyses (for a review see Ostrove, 1990; Davison, 1991).

VZV DNA carries four open reading frames (ORF4, ORF61, ORF62 and ORF63) which encode proteins exhibiting similarities in sequence with HSV-1 immediate-early regulatory proteins (Davison $\&$ Scott, 1986). Two of these proteins (the gene products of ORF61 and ORF62) can complement their HSV-1 homologues ICPO and ICP4 (Disney \& Everett, 1990; Moriuchi et al, 1992); VZV ORF4encoded protein (IE4), on the other hand, appears to be functionally distinct from HSV-1 ICP27 (Moriuchi el al, 1994; Perera et al, 1994). Little is known regarding the functional relationship between IE63 and HSV-1 ICP22. No HSV-1 ICP47 homologue has been proposed in VZV. These four proteins display regulatory functions in transient assays; moreover, ORF61p excepted, all have been classified as immediate-early proteins (Forghani et al, 1990; Debrus et al, 1995; S. Debrus, P. Defechereux, B. Rentier and J. Piette, unpublished results). Cooperative interactions amongst VZV putative immediateearly proteins are likely events (Perera et al, 1992a; Hay \& Ruyechan, 1994). IE62, defined as a major regulatory protein, can transactivate the expression of VZV genes of all three putative kinetic classes (immediate-early, early and late) (Inchauspe el al., 1989; Inchauspe \& Ostrove, 1989; Perera et ah, $1992 a, b$; Baudoux et al, 1995) and autoregulate its promoter (Disney et ah, 1990; Perera et ah, $1992 b$ ). IE4, which possesses transactivating properties on various promoters when transfected alone, can enhance activation by IE62 when both proteins are expressed (Inchauspe et ah, 1989; Inchauspe \& Ostrove, 1989; Perera et ah, 1992a; Defechereux et ah, 1993; Moriuchi et ah, 1994). Depending on the cell line, ORF61p is a transactivator of VZV promoters in the absence of other viral regulators but is a repressor of IE4- and IE62-mediated activation (Nagpal \& Ostove, 1991; Moriuchi et ah, 1992, 1993; Perera et ah, 1992a). IE63 can inhibit activation by IE62 or IE4 (S. Debrus, P. Defechereux, B. Rentier and J. Piette, unpublished data; Hay \& Ruyechan, 1994). In the lytic cycle, these different activities could be coordinated to lead to effective virus production. Similar DNA transfection studies performed on HSV-1 have led researchers to investigate cooperativity among immediate-early proteins ICPO, ICP4 and ICP27 (Sekulovich et ah, 1988; Su \& Knipe, 1989; Zhu et ah, 1994). One approach has b een to address intracellular localization of the proteins in the presence of each other. In transient assays, ICPO and ICP4, which are both nuclear when present individually, can act synergistically to transactivate gene expression (Sekulovich et ah, 1988); in contrast, ICP27 (also nuclear), which 
displays little or no activity on its own, can positively or negatively modulate virus gene expression induced by ICP4 and ICPO (Sekulovich et ah, 1988; Su \& Knipe, 1989). Immunofluorescence assays (IFA) performed in Vero cells infected with wild-type or various mutant viruses indicated that ICP27 has a significant inhibitory effect on the nuclear localization of ICP4 and ICPO (Zhu et ah, 1994; Zhu $\&$ Schaffer, 1995). This effect was confirmed in transient assays with pairs of plasmids expressing wild-type forms of the proteins (Zhu \& Schaffer, 1995). In contrast, staining pattern analyses performed in cotransfected Vero cells demonstrated (i) that ICP4 promotes the nuclear entry of ICPO and (ii) that ICPO influences the intranuclear localization of ICP4, with both proteins being shown to colocalize in discrete punctate structures (Mullen et ah, 1995). Moreover, there is now evidence for a physical interaction between ICPO and ICP4, adding to the observations of mutual influence on their subcellular distribution (Yao \& Schaffer, 1994). Hence, another dimension of gene expression regulation has been revealed in HSV-1 infection, possibly linking function to intracellular location. VZV IE62 is located in nuclei of infected (Forghani et ah, 1990) and transfected cells (Baudoux et ah, 1995), whereas IE4 is mainly distributed in the cytoplasm (Moriuchi et ah, 1995). A possible means for IE4 to perform some of its regulatory functions is to be transported into nuclei by other proteins such as IE62. In this report, we have used double-label IFA to investigate the mutual influence of IE4 and IE62 on their intracellular localization in VZV-infected or DNA-transfected Vero cells.

\section{METHODS}

Cells, virus and infections.

Vero cells were grown at $37{ }^{\circ} \mathrm{C}$ in Medium 199 supplemented with $10 \%$ heat-inactivated fetal calf serum. VZV strain Ellen was propagated by mixing trypsinized VZV-infected cells with non-infected cells at a 1:4 ratio. To perform IFA, Vero cells were plated in 8-5 mm diameter 24-well cluster dishes containing sterile glass coverslips the day before infection. When confluent, cells were overlaid with VZV-infected Vero cells at a 1:4 ratio. Infected monolayers reaching 60\% CPE were used for IFA.

\section{Plasmids and antibodies.}

Plasmids expressing VZV IE proteins under the control of the cytomegalovirus (CMV) major IE promoter (pCMV4, pCMV61 and pCMV63) were kindly provided by P. Kinchington (University of Pittsburgh, Penn., USA). pGi4 contains a single copy of ORF4 driven by its cognate promoter (Inchauspe et al, 1989). IE62 was expressed from pSV62 (Disney et al, 1990). pHN570, pHN1137 and $\mathrm{p} \Delta 612-865$, which are insertion and deletion mutants of IE62, are described in Baudoux et al (1995); mutant pHN570 contains an in-frame insertion after codon 570 of IE62 and mutant pHN1137 contains an in-frame insertion after codon 1137 of IE62. The in-frame deletion mutant p $\Delta 612-865$ was constructed by removing the region extending from codon 612 to 865 in the IE62 protein using Hpal and Nrul restriction enzymes.

In order to detect IE4, a rabbit polyclonal antiserum (VZVIE4) was raised against a synthetic branched peptide of sequence H-SKRDAR-RERIRKE-OH (aa 169-181) according to described procedures (McLean et al,, 1991). To follow IE62, VZVIE62, a mouse monoclonal antibody specific for IE62, was purchased (Viro). A rabbit polyclonal antiserum (iep1278) directed against a synthetic peptide corresponding to the $\mathrm{C}$ terminus of IE62 (kindly supplied by P. Jacobs, University of Brussels, Belgium) was also used. Previously generated rabbit antiserum against IE63 was used to follow IE63 intracellular distribution (Debrus et ah, 1995). ORF61p was visualized with anti-61 serum generously provided by A. Davison (University of Glasgow, UK).

\section{Transfections.}

Vero cells were seeded in 8-5 mm diameter 24-well cluster dishes containing sterile glass coverslips 16 $\mathrm{h}$ prior to transfection with LipofectAMINE according to the manufacturer's instructions (Gibco BRL). IE expression plasmids (2 g) were either transfected alone or in combination, with the total amount of DNA kept constant in each experiment by the addition of sonicated herring sperm DNA. At $24 \mathrm{~h}$ posttransfection the medium was replaced and at $48 \mathrm{~h}$ post-transfection cells were fixed and processed for single- or double-label IFA. 


\section{Immunofluorescence studies.}

Transfected or infected Vero cells grown on coverslips as described above were washed twice in cold PBS, fixed for $20 \mathrm{~min}$ in 1:1 acetone:methanoI (v/v) and immediately stored at $-20^{\circ} \mathrm{C}$. To perform the single- or double-label indirect IFA, cells were rehydrated in PBS/dry milk (3\% w/v) for $30 \mathrm{~min}$ at room temperature before the primary antibodies were added. Dilutions of primary antibodies in PBS/dry milk were: VZVIE4, 1:10; MAb VZVIE62, 1:60; iep1278, 1:250; VZVIE63, 1:100; and VZVIE61, 1:20. Incubation was performed at $37^{\circ} \mathrm{C}$ for $60 \mathrm{~min}$. Following three washes in PBS, incubation was continued with the secondary antibodies, FITC-conjugated swine anti-rabbit (1:40) (Dako) and/or Texas Red-conjugated sheep anti-mouse (1:30) (Amersham) for $45 \mathrm{~min}$ at $37^{\circ} \mathrm{C}$. In single-label IFA, secondary FITC-conjugated swine anti-rabbit antibody was incubated with $1 \%(\mathrm{w} / \mathrm{v})$ Evans blue as counterstaining. Coverslips were then rinsed three times in water and mounted on glass slides with Fluoprep (bioMérieux) to prevent quenching of fluorescence. Processed coverslips were viewed under a Leitz fluorescence microscope equipped with $40 \mathrm{x}$ and $100 \mathrm{x}$ water objective lenses and fitted with adequate filter sets for detection of the two chromophores used. Pictures were taken with Fuji Sensia 400 film.

\section{RESULTS}

\section{IE62 influences the subcellular distribution of the IE4 protein in transfected cells}

IE4 has been shown to be a strong transactivator of VZV and heterologous gene expression in transient transfection assays (Inchauspe et al., 1989; Inchauspe \& Ostrove, 1989; Perera et al., 1992a; Defechereux et al., 1993). Cotransfection experiments demonstrated the capacity of this protein to enhance the activation seen with IE62 on VZV gene promoters refractory to IE4 alone (Perera et ah, 1992 a). One possible mechanism of such a stimulation is that an interaction occurs between these two proteins, thereby influencing their intracellular localization. This hypothesis was addressed in the absence of other regulatory proteins in cotransfection experiments with plasmids expressing intact IE4 and IE62 in Vero cells. The intracellular distribution of these proteins was examined by single- and double-label IF A.

First, cells were transfected only with plasmid pGi4, which carries ORF4 under the control of its cognate promoter (Inchauspe et a/., 1989). It should be noted that the number and intensity of positively labelled cells was rather low $(<1 \%)$. Such a situation has been repeatedly observed with ICP27 under the control of its cognate promoter (Mears et al, 1995; Zhu \& Schaffer, 1995). In contrast, transfection with the IE62-expressing plasmid alone led to a higher number of positive cells $(>10 \%)$. Since ORF62 was under the control of a simian virus 40 promoter more powerful than the ORF4 cognate promoter, a plasmid expressing IE4 from the strong CMV promoter (pCMV4) was also assayed in an attempt to increase IE4 expression levels and to verify whether IE4 concentrations influence intracellular localization. In single transfections with pCMV4, a marked increase in the number of transfected cells was observed compared to pGi4 (>10\%) without alteration of the intracellular pattern (data not shown). Increasing the amounts of both ORF4 vectors (4 and $10 \mathrm{~g}) \mathrm{did}$ not change the subcellular distribution of the protein (data not shown). The distribution of IE4-specific fluorescence was determined by counting immunofluorescence-positive cells and placing them in one of the following categories: cells exhibiting exclusively cytoplasmic staining, cells exhibiting exclusively nuclear staining or cells exhibiting nuclear and cytoplasmic staining with cytoplasmic fluorescence either greater than, equal to, or less than nuclear fluorescence. Table 1 gives the average percentage of cells which fell into each subclass after transfection with pCMV4. IE4 staining (Fig. 1) was predominantly cytoplasmic $(55-8 \%)$ or cytoplasmic and nuclear, with staining in the nucleus weaker than in the cytoplasm $(27.5 \%)$. Some dots of higher intensity were frequently present in the nuclei of these cells. These differences in staining might be partially explained by the transfection conditions and do not necessarily reflect normal infection patterns because of the absence of interactions and regulation by other virus proteins. Cells individually transfected with pSV62 showed essentially diffuse nuclear fluorescent staining (Baudoux et al., 1995).

In the presence of IE62, IE4 intracellular distribution was modified as shown in Table 1, which 
summarizes the categorization of cells exhibiting IE4-specific fluorescence in a set of independent cotransfection experiments conducted with 2 g pCMV4 and 2 g pSV62. Monolayers were doubly stained for IE4 and IE62. IE4-expressing cells were counted and placed in categories as described above. IE62-specific staining was extensive and diffusely nuclear in transfected cells with nucleolar exclusion (Fig. 2a,c). Ten percent of cells exhibited IE62 in the cytoplasm, many of which only displayed intense fluorescence in the endoplasmic reticulum.

Table 1. Intracellular localization of IE4 after cotransfection with plasmids expressing wild-type or mutant forms of IE62

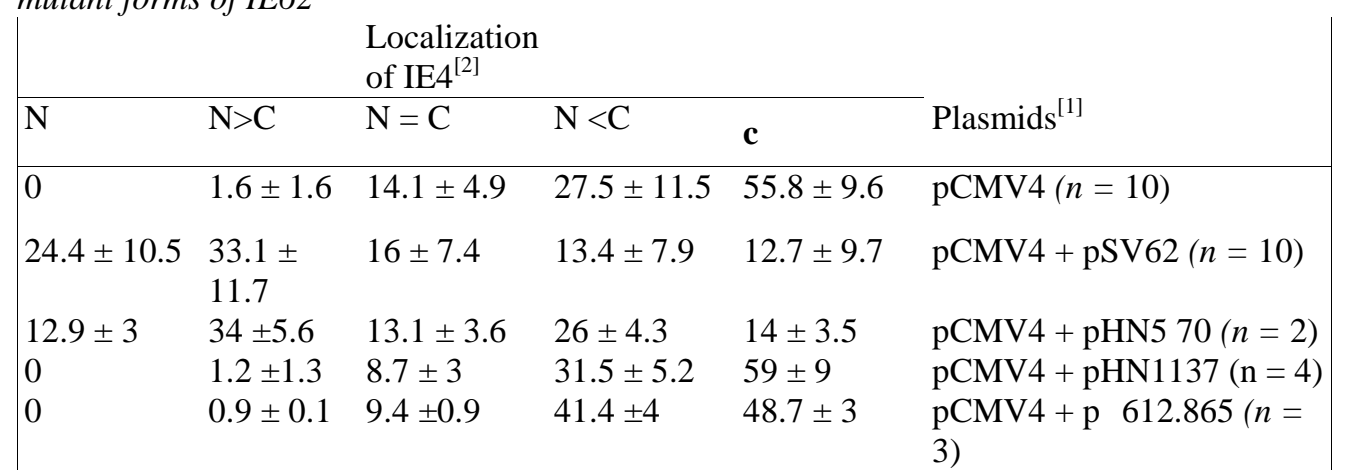

${ }^{[2]}$ Percentages of IE4-positive cells in each pattern of staining (as described in legend to Fig. 1) were determined in several independent experiments. Averages and SD (SEM for $\mathrm{pCMV4)}$ of $n$ independent experiments are presented.

${ }^{[1]}$ Effector plasmids (2 g/ml each) used were as follows: IE4, pCMV4; wild-type IE62, pSV62; mutant IE62 polypeptides, pHN570 (insertion in region 2), pHN1137 (insertion at the border of region 4 and 5) and p $612-865$ (deletion of region 3 and part of region 4$)$.

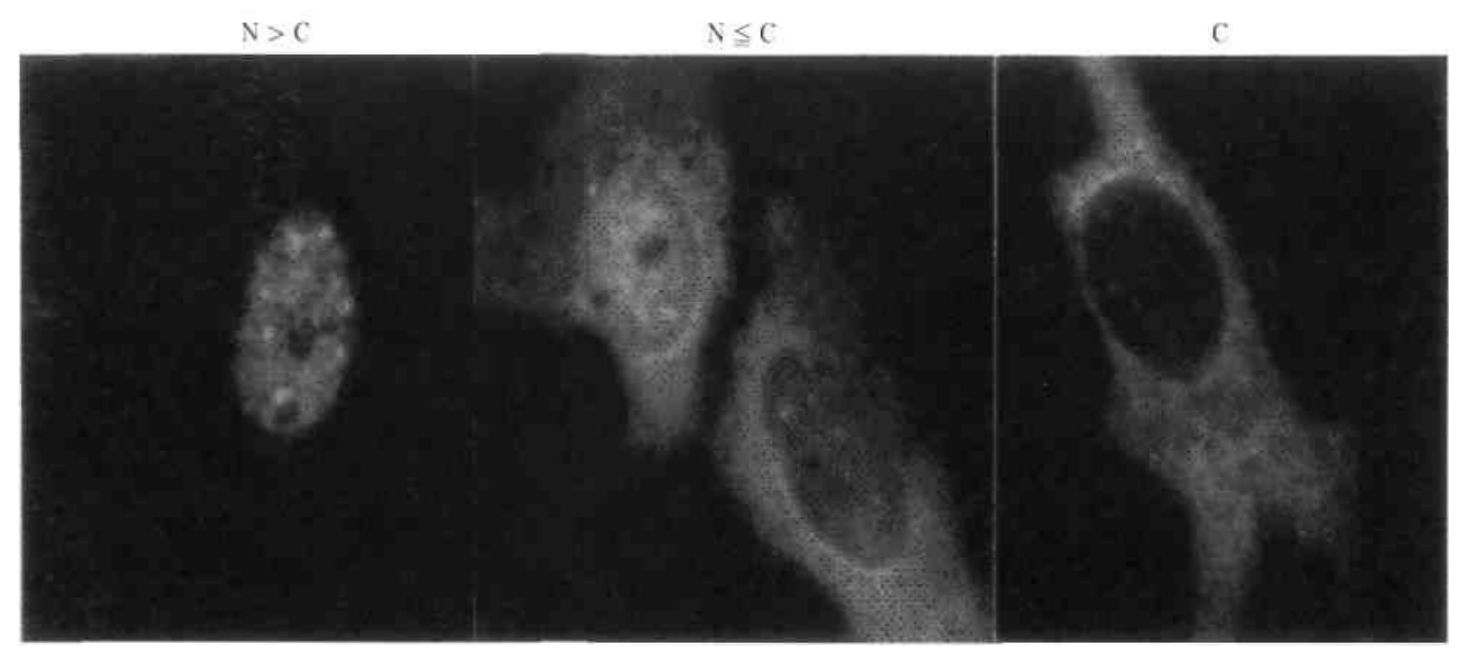

Fig. 1. Intracellular distribution of IE4 protein in Vero cells transfected with IE4 expression vector. Cells were transfected with 2 g of pCMV4. Indirect IFA was performed with rabbit antiserum VZVIE4 and FITC-conjugated swine anti-rabbit IgG. Immunofluorescence-positive cells were counted and categorized in one of five groups: cells that exhibited only nuclear staining $(N)$; nuclear staining greater $(N>C)$, equal $(N=C)$ or less $(N<C)$ than cytoplasmic staining; or cytoplasmic staining only (C). The average percentage and SEM of cells belonging to each category was calculated from 10 independent transfection experiments and is given in Table 1. Examples of each category except $N$ are illustrated; $N \leq C$, nuclear staining equal to or less than cytoplasm staining.

When IE62 was present in nuclei, the percentage of cells exhibiting IE4 nuclear staining (Fig. $2 b$ ) and, most predominantly, cells with nuclear staining more intense than cytoplasmic staining (Fig. $2 d$ ) increased significantly, while the percentage of cells with cytoplasmic staining decreased (see Table 1). Statistical analysis of the results of 10 experiments with the $\chi^{2}$ test for association showed that IE4 and IE62 distributions were not independent. Generally, high levels of IE62 expression in nuclei (very intense fluorescence, Fig. $2 a$, c) correlated with the presence of IE4 in the nucleus, whereas lower levels of IE62 fluorescence were found in cells where IE4 was only cytoplasmic (data not shown). This suggests that a certain critical IE62 concentration could be required for nuclear translocation of IE4. 
The CMV promoter in pCMV4 is very poorly stimulated by IE62 (Baudoux et al., 1995) so transactivation of IE4 expression is unlikely to be responsible for the observed changes in its intracellular distribution.

In these experiments, it was very striking that no significant alteration of IE62 intracellular localization was observed in response to the presence of IE4. The proportion of IE62-positive nuclei remained identical whether IE4 was expressed or not.

\section{Intracellular localization of IE4 and IE62 in VZV-infected cells}

In order to compare observations made in transient transfection assays with the physiological localization of IE62 and IE4 during infection, Vero cells were infected with VZV strain Ellen and processed for double-label immunofluorescence in order to detect IE4 and IE62 simultaneously. IE62 was most prominent in the nuclei of infected cells, as previously described by Forghani et al. (1990). Some nuclei showed intense globular staining, probably correlating with replication compartments. The staining pattern for IE4 in these cells was mainly cytoplasmic but in numerous infected cells, a slight staining with occasionally intense fluorescent dots could be detected in the nuclei (resembling the $\mathrm{C}$ and $\mathrm{N} \leq \mathrm{C}$ patterns seen in Fig. 1). In certain cases, these dots were found also to contain IE62 (data not shown). These observations were reproduced in MRC5 cells, another cell line used to grow VZV in our laboratory (S. Debrus, P. Defechereux, B. Rentier and J. Piette, unpublished results).

ORF61 p and IE63 proteins are not capable of inducing nuclear translocation of IE4

ORF61p and IE63 are two VZV regulatory proteins which could intervene in IE4 distribution, since they both possess transactivating and transrepressing properties and can interfere or synergize with IE4 (S. Debrus, P. Defechereux, B. Rentier and J. Piette, unpublished data; Nagpal \& Ostrove, 1991; Perera et al., 1992A; Hay \& Ruyechan, 1994). Transfection experiments were undertaken with pCMV61 or pCMV63, which carry the genes under the control of the powerful CMV promoter/enhancer. To detect ORF61p and IE63, IFA were performed in individually transfected cells with rabbit antisera VZVIE61 and VZVIE63, respectively. 

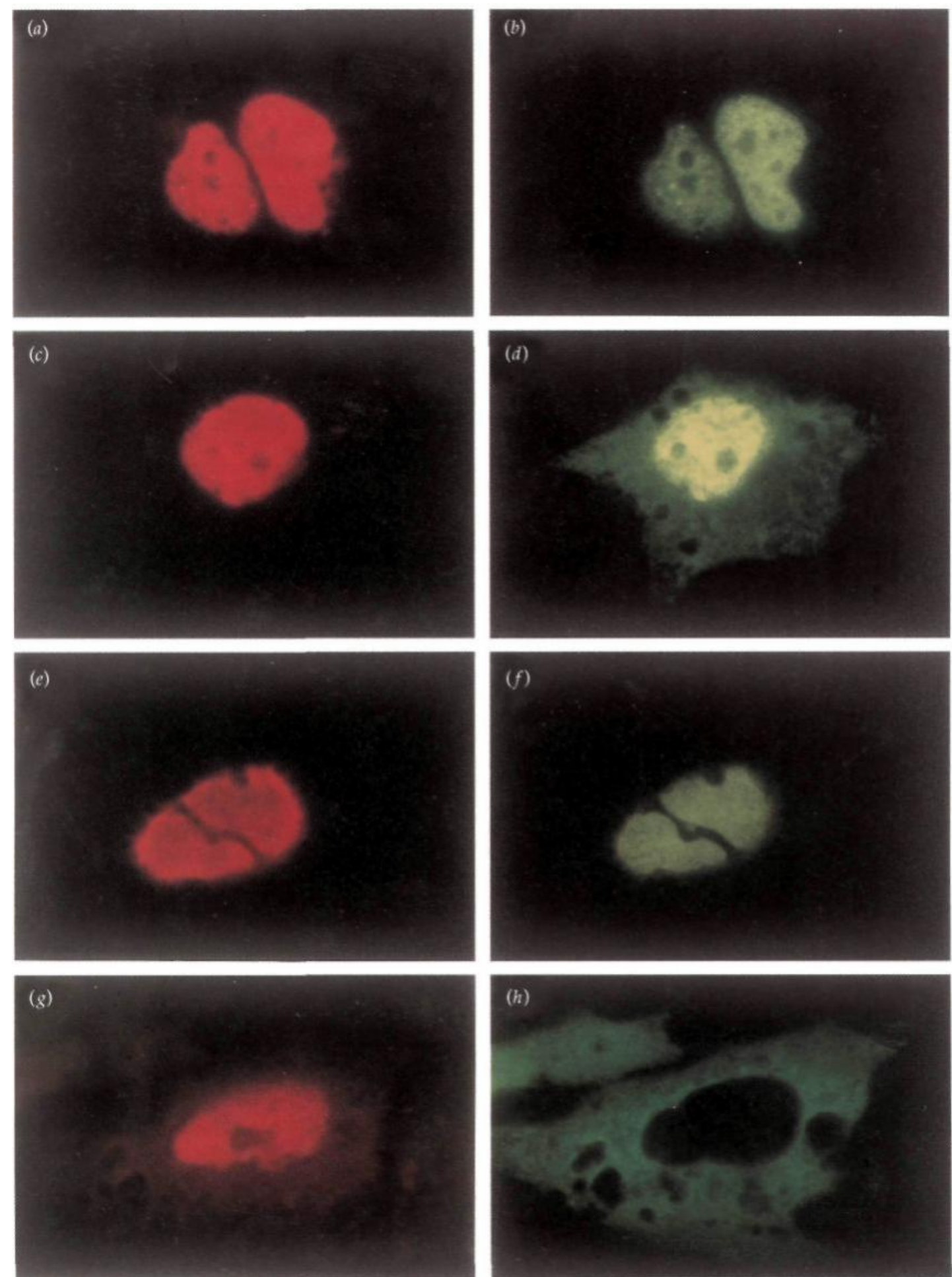

Fig. 2. Intracellular distribution of IE4 and IE62 proteins after cotransfection with IE4 and wild-type or mutant IE62 expression vectors. Monolayers were transfected with 2 gof pCMV4 and 2 of pSV62 (a-d), 2 g pHN570 (e-f) or 2 g pHN1 $137(g-h)$. Coverslips were incubated with a mixture of MAb VZVIE62 $(a, c, e, g)$ and antiserum VZVIE4 $(b, d, f, h)$ as primary antibodies, then incubation was pursued with FITC-conjugated swine anti-rabbit IgG and Texas Red-conjugated sheep anti-mouse IgG as secondary antibodies. 
Table 2. Intracellular localization of IE4 after cotransfection with plasmids expressing ORF61p or lE63

\begin{tabular}{|c|c|c|c|c|c|c|c|}
\hline \multirow[b]{2}{*}{ Expt } & \multicolumn{7}{|c|}{$\begin{array}{l}\text { Localization of } \\
\text { IE4* }\end{array}$} \\
\hline & Number $^{\mathrm{t}}$ & $\mathrm{N}$ & $\mathrm{N}>\mathrm{C}$ & $\mathrm{N}=\mathrm{C}$ & $\mathrm{N}<\mathrm{C}$ & c & Plasmids $^{\mathrm{f}}$ \\
\hline \multirow[t]{2}{*}{1} & 434 & 0 & $0 ' 7$ & 10 & 19 & 70.3 & $\begin{array}{l}\text { pCMV4 + } \\
\text { pCMV61 }\end{array}$ \\
\hline & 506 & 0 & 1 & 11.9 & 48 & 39.1 & $\begin{array}{l}\text { pCMV4 + } \\
\text { pCMV63 }\end{array}$ \\
\hline \multirow[t]{2}{*}{2} & 263 & 0 & 1.4 & 14.1 & 36.4 & 48.1 & $\begin{array}{l}\text { pCMV4 + } \\
\text { pCMV61 }\end{array}$ \\
\hline & 283 & 0.4 & 3.8 & 10.7 & 28.1 & 57 & $\begin{array}{l}\text { pCMV4 + } \\
\text { pCMV63 }\end{array}$ \\
\hline
\end{tabular}

In transfected cells, ORF61p-associated fluorescence displayed a diffuse pattern with intense dots, reminiscent of that of infected cells (Stevenson et al., 1992) and of its HSV-1 homologue ICP0 (Mullen et al., 1995). IE63 staining was found with greater intensity in the nuclear compartment than in the cytoplasm, as had previously been shown in infected cells (Debrus et al., 1995). The number of positive cells was usually high, reflecting efficient transient expression. Cotransfection experiments involving pCMV63 or pCMV61 and pCMV4 were then conducted. To ensure the conditions of transfection were appropriate for IE4 translocation, a control cotransfection with pSV62 was conducted in parallel. Cotransfected coverslips were analysed in parallel with antibodies VZVIE63 or VZVIE61 and VZVIE4 (data not shown). IE4-positive cells were counted and assigned to the different categories (Table 2). In neither case was IE4 found to be transported in nuclei, in contrast to the situation with wild-type IE62. Therefore, translocation to the nucleus is not an artifact resulting from cotransfection with regulatory proteins and seems specific to cotransfection with the major regulatory protein IE62. The presence of IE4 did not influence IE63 or ORF61p intracellular localizations in our cotransfection system (data not shown).

\section{Effect of IE62 mutants on IE4 intracellular localization}

In an attempt to elucidate the mechanism through which IE62 affects IE4 subcellular localization and to distinguish between promoter transactivation and other direct or indirect influences, cotransfection experiments with three plasmids (derived from pSV62) encoding mutant IE62 polypeptides and the pCMV4 vector were carried out. Expression vector pHN5 70 contains an in-frame insertion after the 5 70 codon of ORF62. This mutation is located in region 2 (the DNA-binding domain; Wu \& Wilcox, 1991) and results in the loss of IE62 transactivating properties (Baudoux et al., 1995). IFA on pHN5 70-transfected cells showed diffuse nuclear staining with two or more intense fluorescent regions, somewhat different to the diffuse nuclear staining observed with wild-type IE62 (Fig. 2e). When pHN570 and pCMV4 were cotransfected, the overall distribution of IE4-specific fluorescence resembled that of cells cotransfected with wild-type IE62 and pCMV4 (Table 1). IE4 colocalized with the mutant polypeptide in the nuclear regions (Fig. $2 e, f$ ). The influence of IE62 on IE4 localization was clearly not dependent on its transactivating property.

To confirm this observation, pHN1137, another IE62 mutant which carries an insertion at codon 1137 in the C-terminal end of region 4 (Baudoux et al., 1995) and has lost most its transactivating activity, was tested. The mutant protein encoded by pHNH37 exhibited similar diffuse nuclear staining to wildtype IE62 (Fig. $2 g$ ). Interestingly, pHNH37 seemed incapable of directing IE4 to the nuclei of transfected cells (Fig. $2 h$ ). The distribution of IE4-positive cells was identical to that of IE4 vector alone (Table 1). This suggested that the region around amino acid 1137 of IE62 might play an important role in the translocation mechanism.

Finally, p $\Delta 612-865$, a deletion mutant lacking the whole region 3, which contains a putative nuclear localization signal (NLS; Baudoux et al., 1995), and part of region 4, was cotransfected with IE4. $\mathrm{p} \Delta 612-865$ has lost the epitope recognized by MAb VZVIE62, since no fluorescence was detected in double-label IFA. Therefore, coverslips were treated separately with iepl278 and VZVIE4. p $\Delta 612-865$ 
is clearly cytoplasmic (Baudoux et al., 1995) and unable to induce nuclear translocation of IE4 (Table 1). Therefore, loss of this region, either intrinsically or through the influence it has on overall IE62 integrity, prevents the translocation of IE4 into the nucleus.

\section{DISCUSSION}

The present study focused on characterizing VZV IE4 protein intracellular distribution in the presence of IE62. It showed that IE62 could influence the intracellular localization of IE4 in transfected cells: when IE62 was present, IE4 became more nuclear.

In the course of productive infection, IE4 was mainly cytoplasmic, although a slight IE4-specific staining could also be found in nuclei. In nuclei of infected Vero and MRC5 cells (S. Debrus, P. Defechereux, B. Rentier and J. Piette, unpublished results), IE62 was frequently distributed in dots or speckles which were sometimes also found to contain IE4. One explanation as to why not all cells within foci displayed overlapping fluorescent signals might be that such an event occurs only at precise times during the course of virus replication and is dependent upon regulatory protein concentrations. To understand the apparent differences between the observations made in infected and in cotransfected cells, the particular conditions associated with analysis of protein functions in vitro should be taken into consideration. Most importantly, the absence of other virus proteins which could influence IE4 and/or IE62 expression and localization must be acknowledged. Recent data acquired in our laboratory clearly indicate a down-regulatory activity of IE63 on IE4 trans-activation (S. Debrus, P. Defechereux, B. Rentier and J. Piette, unpublished results), which could influence IE4 expression levels in VZVinfected cells. Availability of VZV mutants should help to clarify the physiological relevance of such in vitro observations.

ICP4 and ICP27, which both possess NLS, are found predominantly in nuclei of HSV-1-infected cells, with ICP4 present in replication compartments (Mears et al., 1995; Zhu \& Schaffer, 1995). In light of our observations, VZV IE4 locates differently from HSV-1 ICP27. Therefore, despite sequence similarities, these proteins are different in their localization and, at least partially, in their functions (Moriuchi et ah, 1995).

In transfected cells, IE4 tends to locate in the cytoplasm and in the nucleus, with intensity of nuclear staining weaker than in the cytoplasm. Recent findings suggest that the N-terminal portion (1-403) of the molecule contains a NLS, although no sequence has been proposed (Moriuchi et al., 1995). By computer search analysis, we have found a putative bipartite signal, RRSSRSYNTQSSRKHRDR, between amino acids 118 and 134. This sequence is located at a position similar to that of the recently defined ICP27 NLS (aa 110-137) (Mears et al, 1995). The function of this putative NLS needs to be experimentally determined. The $\mathrm{C}$ terminus (aa 404-452) appears to play a role in the cytoplasmic distribution of the protein, since a truncation mutant lacking this region was exclusively localized in the nucleus in a speckled pattern with nucleolar exclusion (Moriuchi et al., 1995). In our experiments, a speckled arrangement was observed in the nuclei of a few cells transfected with pCMV4 alone; however, in such cases, diffuse cytoplasmic staining was present. Interestingly, no speckles were ever detected in the cytoplasm. The IE4 protein seems to possess an intrinsic capacity to be directed to the nucleus, under undefined conditions, possibly involving its $\mathrm{C}$ terminus.

IE4-specific staining observed in nuclei when IE62 was present was usually diffuse, similar to a chimeric construct between IE4 amino acids 1-403 and ICP27 amino acids 465-512 (Moriuchi et al., 1995). Therefore, in cotransfected cells, IE62 might participate in alleviating the influence of the IE4 C-terminal region on cytoplasmic localization. In view of our results, a certain critical IE62 expression level is apparently required for the nuclear localization of IE4, since the presence of IE62 in the nucleus did not always correlate with colocalization. Such dependence has been shown in the case of the influence of ICP27 on ICP4 nuclear localization (Zhu \& Schaffer, 1995).

It should be noted that although IE4 becomes more nuclear when IE62 is present, translocation to the nuclei is not complete. The IE62-mediated effect could be direct or indirect. The influence of IE62 on IE4 localization is not dependent on enhancement of IE4 expression, since a mutant IE62 protein expressed from pHN570, which has lost its transactivating properties, was still capable of driving IE4 to the nucleus. Quite interestingly, the other mutants specified by pHN1137 and p $\Delta 612-865$ were not able to influence IE4 distribution. The modification around amino acid 1137 altered the IE62 protein in such a way as to impair the translocation mechanism. Protein stability or folding might be affected, interfering with a direct interaction with IE4 or indirect interactions with cellular proteins required in post-translational modification of IE4. The mutation is situated in region 4, which is homologous to IE62 and ICP4 (McGeoch et al, 1986; Baudoux et al, 1995). Recently, Yao \& Schaffer (1994) have shown that the C-terminal 235 amino acids (1064-1298) of ICP4 are important for efficient protein- 
protein interaction with ICP0. Therefore, region 4 of IE62 could possibly be a functional domain involved in physical interaction. Further experiments to provide evidence of such specific interactions are necessary to support this hypothesis. Analysis of p $\Delta 612-865$ confirmed the importance of IE62 functions, as it also seems incapable of directing IE4 to the nucleus from the cytoplasm. The deleted region might contain signals critical for this purpose.

Previous studies conducted with HSV-1 proteins ICP4, ICP27 (Zhu \& Schaffer, 1995) and ICP0 (Zhu et $a \downarrow, 1994$ ) have shown that (i) ICP27 negatively influences the nuclear localization of ICP4 and ICP0; (ii) the C-terminal half of ICP27 is required for this function; (iii) the localization and level of expression of ICP27 are critical for the influence on ICP4 distribution; and (iv) residues between amino acids 820 and 1029 of the ICP4 molecule are responsive to the negative effect of ICP27. These observations and our results taken collectively provide new evidence of differences between IE4 and ICP27 regarding intracellular localization and interactions with other regulatory proteins. IE4 neither influenced IE62 intracellular localization nor modified that of ORF61p. Major importance is attributed to the C-terminal region of ICP27 in regulatory functions (Hardwicke et al., 1989; McMahan \& Schaffer, 1990) and to directing ICP4 to the cytoplasm (Zhu \& Schaffer, 1995). This portion of the IE4 molecule also appears to be crucial for its properties (Perera et al., 1994). There is little functional complementarity between the C-terminal portions of ICP27 and IE4 (Moriuchi et a/., 1995), leading to the suggestion that the different behaviours observed could be associated with the specificity of each $\mathrm{C}$ terminal region in the context of their native proteins.

We have shown, in transient transfection assays, that IE62, but not IE63 or ORF61p, can influence IE4 repartition between intracellular compartments. Although the mechanisms are at present unclear, this effect can possibly be correlated with the synergy observed between these two virus regulators in various CAT assays. Interestingly, IE4 seems incapable of influencing IE62 intracellular distribution. Our observations in infected and transfected cells add evidence of differences between closely related IE4 and ICP27 of HSV-1.

\section{Acknowledgments}

We thank Dr Andrew Davison for VZVIE61 and Dr Paul Jacobs for iepl278. We are grateful to Dr Paul Kinchington (University of Pittsburgh, Penn., USA) for providing plasmids pCMV4, pCMV61 and pCMV63 and to Dr Jef M. Ostrove for pGi4. pSV62 was generously provided by Dr Roger Everett. IE4 branched peptide was synthesized by A. Michel (Universite de Mons, Belgium). We thank Paul Gerard for statistical analysis of results and Douglas Craig for careful reading of the manuscript. This work was supported by grants from the Belgian National Fund for Scientific Research (FNRS; Brussels, Belgium), the Concerted Action Program (Communaute Francaise de Belgique; Brussels, Belgium) and SmithKline Beecham Biologicals (Rixensart, Belgium). P.D. is supported by a FNRS - SmithKline Beecham Biologicals grant. S.D. was supported by the FRIA (Brussels, Belgium) and the Anti Cancer Center Fund (Liege, Belgium), L. B. and S. S. were supported by the Concerted Action Program. J. P. and M.-P. M.-L. are respectively Research Director and Research Associate of the FNRS.

\section{References}

Baudoux, L., Defechereux, P., Schoonbroodt, S., Merville-Louis, M.-P., Rentier, B. \& Piette, J. (1995). Mutational analysis of varicella-zoster virus major immediate-early protein IE62. Nucleic Acids Research 23, 1341-1349.

Davison, A. J. (1991). Varicella-zoster virus, journal of General Virology 72, 475—486.

Davison, A. J. \& Scott, J. E. (1986). The complete DNA sequence of varicella-zoster virus. Journal of General Virology 67, $1759-1816$.

Debrus, S., Sadzot-Delvaux, C, Nikkels, A., Piette, J. \& Rentier, B. (1995). Varicella-zoster virus gene 63 encodes an immediateearly protein abundantly expressed during latency. Journal of Virology 69, 3240-3245.

Defechereux, P., Melen, L., Baudoux, L., Merville-Louis, M.-P., Rentier, B. \& Piette, J. (1993). Characterization of the regulatory functions of varicella-zoster virus open reading frame 4 gene product. Journal of Virology 67, 4379-4385.

Disney, G. H. \& Everett, R. D. (1990). A herpes simplex virus type 1 recombinant with both copies of the Vmwl75 coding sequences replaced by the homologous varicella-zoster virus open reading frame. Journal of General Virology 71, 2681-2689.

Disney, G. H., McKee, T. A. \& Everett, R. D. (1990). The product of varicella-zoster virus gene 62 autoregulates its own promoter. Journal of General Virology 71, 2999-3003. 
Forghani, B., Mahalingam, R., Vafai, A., Hurst, J. W. \& Dupuis, K. W. (1990). Monoclonal antibody to immediate-early protein encoded by varicella-zoster virus gene 62. Virus Research 16, 195-210.

Hardwicke, M. A., Vaughan, P. J., Sekulovich, R. E., O'Conner, R. \& Sandri-Goldin, R. M. (1989). The region important for the activator and repressor functions of herpes simplex virus type $1 \alpha$ protein ICP27 map to the C-terminal half of the molecule. Journal of Virology 63, 4590-4602.

Hay, J. \& Ruyechan, W. T. (1994). Varicella-zoster virus - a different kind of herpesvirus latency? Seminars in Virology 5, $241-247$

Honess, R. W. \& Roizman, B. (1974). Regulation of herpesvirus macromolecular synthesis. I. Cascade regulation of the synthesis of three groups of viral proteins. Journal of Virology 14, 8-19.

Honess, R. W. \& Roizman, B. (1975). Regulation of herpesvirus macromolecular synthesis: sequential transition of polypeptide synthesis requires functional polypeptides. Proceedings of the National Academy of Sciences, USA 72, 1276-1280.

Inchauspe, G. \& Ostrove, J. M. (1989). Differential regulation by varicella-zoster virus (VZV) and herpes simplex virus type-1 trans-activating genes. Virology 173, 710-714.

Inchauspe, G., Nagpal, S. \& Ostrove, J. M. (1989). Mapping of two varicella-zoster virus-encoded genes that activate the expression of viral early and late genes. Virology 173, 700-709.

McGeoch, D. J., Dolan, A., Donald, S. \& Braver, D. H. K. (1986)

Complete DNA sequence of the short repeat region in the genome of herpes simplex virus type 1. Nucleic Acids Research 14, $1727-1745$

McLean, G. W., Owsianka, A. M., Subak-Sharpe, J. H. \& Marsden, H. S. (1991). Generation of anti-peptide and anti-protein sera: effect of peptide presentation on immunogenicity. Journal of Immunological Methods 137, 149-157.

McMahan, L. \& Schaffer, P. A. (1990). The repressing and enhancing functions of the herpes simplex virus regulatory protein ICP27 map to C-terminal regions and are required to modulate viral gene expression very early in infection. Journal of Virology 64, 3471-3485

Mears, W. E., Lam, V. \& Rice, S. A. (1995). Identification of nuclear and nucleolar signals in the herpes simplex virus regulatory protein ICP27. Journal of Virology 69, 935-947.

Moriuchi, H., Moriuchi, M., Smith, H. A., Straus, S. E. \& Cohen, J. I. (1992). Varicella-zoster virus open reading frame 61 protein is functionally homologous to herpes simplex virus type 1 ICP0. Journal of Virology 66, 7303-7308.

Moriuchi, H., Moriuchi, M., Smith, H. A., Straus, S. E. \& Cohen, J. I. (1993). Varicella-zoster virus (VZV) open reading frame 61 protein transactivates VZV" gene promoters and enhances the infectivity of VZV DNA. Journal of Virology 67, 4290-4295.

Moriuchi, H., Moriuchi, M., Smith, H. A. \& Cohen, J. I. (1994). Varicella-zoster virus open reading frame 4 protein is functionally distinct from and does not complement its herpes simplex virus type 1 homolog, ICP27. Journal of Virology 68, $1987-1992$

Moriuchi, H., Moriuchi, M., Debrus, S., Piette, J. \& Cohen, J. I. (1995). The acidic amino-terminal region of varicella-zoster virus open reading frame 4 protein is required for transactivation and can functionally replace the corresponding region of herpes simplex virus ICP27. Virology 207, 376-382.

Mullen, M.-A., Gerstberger, S., Ciufo, D. M., Mosca, J. D. \& Hayward, G. (1995). Evaluation of colocalization interactions between the IE 110, IE175, and IE63 transactivator proteins of herpes simplex virus within subcellular punctate structures. Journal of Virology 69, 476-491.

Nagpal, S. \& Ostrove, J. M. (1991). Characterization of a potent varicella-zoster virus encoded frans-repressor. Journal of Virology 65, 5289-5296.

Ostrove, J. M. (1990). Molecular biology of varicella-zoster virus. Advances in Virus Research 38, 45-99.

Perera, L. P., Mosca, J. D., Ruyechan, W. T. \& Hay, J. (1992 $\alpha$ ). Regulation of varicella-zoster virus gene expression in human T lymphocytes, journal of Virology 66, 5298-5304.

Perera, L. P., Mosca, J. D., Sadeghi-Zadeh, M., Ruyechan, W. T. \& Hay, J. (1992 b). The varicella-zoster virus immediate-early protein, IE62, can positively regulate its cognate promoter. Virology 191, 346-354.

Perera, L. P., Kaushal, S., Kinchington, P. R., Mosca, J. D., Hayward, G. S. \& Straus, S. E. (1994). Varicella-zoster virus open reading frame 4 encodes a transcriptional activator that is functionally distinct from that of herpes simplex virus homolog ICP27. journal of Virology 68, 2468-2477.

Sekulovich, R. E., Leary, K. \& Sandri-Goldin, R. M. (1988). The herpes simplex virus type $1 \alpha$ protein ICP27 can act as a fransrepressor or a trans-activator in combination with ICP4 and ICPO. journal of Virology 62, 4510-4522.

Stevenson, D., Colma, K. L. \& Davison, A. J. (1992). Characterization of the varicella-zoster virus gene 61 protein, journal of General Virology 73, 521-530. 
Published in : Journal of general virology (1996), vol. 77, iss. 7, pp. 1503-1513

Status : Postprint (Author's version)

Su, L. \& Knipe, D. M. (1989). Herpes simplex virus $\alpha$ protein ICP27 can inhibit or augment viral gene transactivation. Virology $170,496-504$

Wu, C. L. \& Wilcox, K. W. (1991). The conserved DNA-binding domains encoded by the herpes simplex virus type 1 ICP4, pseudorabies virus IE180, and varicella-zoster virus ORF62 genes recognize similar sites in the corresponding promoters, journal of Virology 65, 1149-1159.

Yao, F. \& Schaffer, P. A. (1994). Physical interaction between the herpes simplex virus type 1 immediate-early regulatory proteins ICPO and ICP4. journal of Virology 68, 8158-8168.

Zhu, Z. \& Schaffer, P. A. (1995). Intracellular localization of the herpes simplex virus type 1 major transcriptional regulatory protein, ICP4, is affected by ICP27. journal of Virology 69, 49-59.

Zhu, Z.. Cai, W. \& Schaffer, P. A. (1994). Cooperativity among herpes simplex virus type 1 immediate-early regulatory proteins: ICP4 and ICP27 affect the intracellular localization of ICPO. Journal of Virology 68, 3027-3040. 